\title{
Journal of Business and Financial Affairs: Reasons to be an Open Access Journal
}

\section{Guo Ying Luo*}

Guo Ying Luo, DeGroote School of Business, McMaster University, Canada

We, as academic researchers, are often frustrated with the difficulty or inconvenience of obtaining articles from some websites or libraries due to the lack of subscriptions. Also, we are reluctant to hand the copyrights of our research articles to the publishers who otherwise won't publish them. These are the problems. The academic community is aware of these problems. Some universities or academic communities have pushed for an open access model that authors retain all copyrights of their published work and provide free and open access to all users. Open access provides a rapid dissemination of research. The papers published in Open Access journals will be read by more people and consequently have more impact than the ones available only to paid subscribers.

Journal of Business and Financial Affair is a newly launched open access journal published by OMICS publishing Group. This journal projects a relatively new model for scholarly journal publishing that provides worldwide, barrier-free access to the full-text of all published articles. Journal of Business and Financial Affair is an Open Access, peer-reviewed, online journal that focus on an organization or enterprising entity engaged in commercial, industrial or professional activities. The published digital articles are delivered electronically to readers so that readers can listen as well as read the articles. In addition, user friendly website-translation of published articles to more than 50 languages ensures the widest audience possible.

Journal of Business and Financial Affair provides the monthly publication of articles in the areas of business and finance. There is no submission fee and a small fee will be charged to the authors once their papers have been accepted by the journal. Journal of Business \& Financial Affairs uses online manuscript submission, review and tracking systems for quality and quick review processing. The journal completes the review processing in twenty-one days and the publication of the accepted papers occurs within seven days of acceptance.

*Corresponding author: Guo Ying Luo, Ph.D, Associate Professor of Finance Department of Finance and Business Economics, DeGroote School of Business, McMaster University, 1280 Main Street, Hamilton, Ontario, L8S 4M4, Canada, Tel: 905525 9140; E-mail: luogy@mcmaster.ca

Received December 01, 2011; Accepted January 04, 2012; Published January 06, 2012

Citation: Luo GY (2012) Introduction to Journal of Business and Financial Affairs. J Bus Finan Affairs 1:e103. doi:10.4172/2167-0234.1000e103

Copyright: (c) 2012 Luo GY. This is an open-access article distributed under the terms of the Creative Commons Attribution License, which permits unrestricted use, distribution, and reproduction in any medium, provided the original author and source are credited. 